\title{
Innovations
}

\section{Editorial: A global platform for Innovations in Health Professions Education}

\section{Authors}

Javaid I. Sheikh'; Victor J. Dzau²

\section{Editorial}

Strengthening health systems and building capacity through effective workforce development and health professional education are the cornerstones for improving global health. Since the Lancet Commission's 2010 landmark report, " "Health professionals for a new century: transforming education to strengthen health systems in an interdependent world," there has been a groundswell of excitement and activities among health professions educators to carry the momentum forward. Notable major recommendations in the Commission's report validated the needs for a global outlook, alignment with healthcare delivery, an inclusive multiprofessional/trans-professional orientation, a systems-based approach, and new instructional and institutional strategies. A broad receptivity worldwide for such a paradigm-changing approach to health professions education has been facilitated by general dissatisfaction with current healthcare and education globally. There remains a chasm between skill sets needed for providing high quality healthcare and the current fragmented and outdated curricula of health professional education.

The United States Institute of Medicine (now National Academy of Medicine) has established and convened for the last several years an annual global forum on Health Professional Education (HPE). A recent report of the forum titled, "Envisioning the future of Health Professional Education (HPE)" documents detailed recommendations for the curriculum redesign and restructuring needed for a changing global health workforce. $^{2}$

Similarly, the World Health Organization (WHO) in its 2010 report on a "Framework for action on inter-professional education (IPE) and collaborative practice" stressed the importance of IPE to overcome shortages in the healthcare workforce, and to enable effective collaborative practice, thereby, strengthening health systems and improving health outcomes. ${ }^{3}$ Another development has been the formation of an "Interprofessional Education Collaborative" among six national education associations of schools of the health professions (medicine, both allopathic and osteopathic, dentistry, nursing, pharmacy, and public health) to "encourage constituent efforts that would advance substantive interprofessional
1. Dean, Weill Cornell Medical College in Qatar; Professor of Psychiatry, Weill Cornell Medical College in Qatar, Doha, Qatar

2. President, National Academy of Medicine, Washington, D.C.

*E-mail: jsheikh@qatar-med.cornell.edu

\section{Cite this article as:}

Sheiukh Jl, Dzau VJ.. A Global Platform for Innovations in Health Professions Education. Innovations in Global Health Professions Education. 2015:1. http://dx.doi.org/10.20421/ighpe2015.1

This is an open access article distributed under the terms of the Creative Commons Attribution license CC BY 4.0, which permits unrestricted use, distribution and reproduction in any medium, provided the original work is properly cited. 
learning experiences to help prepare future health professionals for enhanced team-based care of patients and improved population health outcomes." ${ }^{4}$ In July 2015, a United States Congressional briefing was also held on IPE. ${ }^{5}$ In summary, there is broad support for an inclusive HPE/IPE model, preparing health professionals for a team-based collaborative approach to healthcare.

It is encouraging to have such broad policy level support for a transformation of the existing HPE to make it more inclusive and trans-professionally oriented, interdependent, and relevant to rapidly changing healthcare trends. However, it will take time to make operational and then test various new instructional and institutional models in differing geographic locales and cultures. Our new initiative, "Innovations in Global Health Professions Education" (IGHPE), will provide an interactive platform to fill this gap. Specifically, IGHPE is meant to be a dynamic platform to test and validate innovative ideas, models, and strategies for health professions education that are globally informed and locally relevant. With an open access journal, a website with dynamic content, and a format for thoughtful debates and discussions, IGHPE will provide an organic process to develop and test ideas and models.

Several converging trends $\mathrm{s}^{6,7,8}$ necessitate the creation of interactive and dynamic web-based platforms,:

Firstly, digital technologies combined with broad acceptance of WiFi-based health assessment tools, and the gathering and transmission of such information to both patients and healthcare providers, are moving the field rapidly toward a model of "participatory, personalized, and preventive medicine."

Secondly, discoveries and breakthroughs in biological sciences (genomics, proteomics, metabolomics, microbiomics, etc.) and advances in informatics are leading to "precision and predictive medicine."

Thirdly, changing economics of healthcare and better-informed patients are pushing healthcare systems to establish key performance indicators (KPIs) for demonstrating good outcomes.
Last, but not the least, transformative changes are afoot in the broad field of education itself, due to increasing recognition of the need for scientific and information technology-based literacy, brand new competencies (e.g., critical thinking, creativity, communication, collaboration, cultural awareness etc.), and preparation for lifelong learning. ${ }^{8}$ All of these will require the implementation and testing of flexible and open curricula and models, as well as rapidly adaptive strategies for training.

As described in Figure 1, IGHPE is a platform for building a broad community of health professions educators who will foster dialogue, debate, and discussion about various innovations as part of regional workshops, international conferences, and articles written in an open access journal. These activities will become a resource for collaborations, partnerships, and consulting. In addition, videos, podcasts, blogs, twitter, and other social and digital media-based communication tools will be used, as needed.

Through IGHPE, we look forward to working with health professionals and educators globally to create a forum for exchange of ideas and knowledge, a resource for collaborations and partnerships, the source for development of new models of learning, and a catalyst for solutions to improve global health through effective education.

\section{References}

1. Frenk, J., L. Chen, Z. A. Bhutta, J. Cohen, N. Crisp, T. Evans, et al. Health professionals for a new century: Transforming education to strengthen health systems in an interdependent world. Lancet 2010;376(9756):1923-1958.

2. The National Academy of Medicine/Institute of Medicine [Internet]. Envisioning the Future of Health Professional Education. Washington D.C.: Institute of Medicine 2015 [cited 2015 November 30]. Available from http://www.nap. edu/catalog/21796/envisioning-the-futureof-health-professional-education-workshopsummary.

3. World Health Organization (WHO) [Internet]. Framework for action on interprofessional 


\section{IGHPE as an organizing platform}

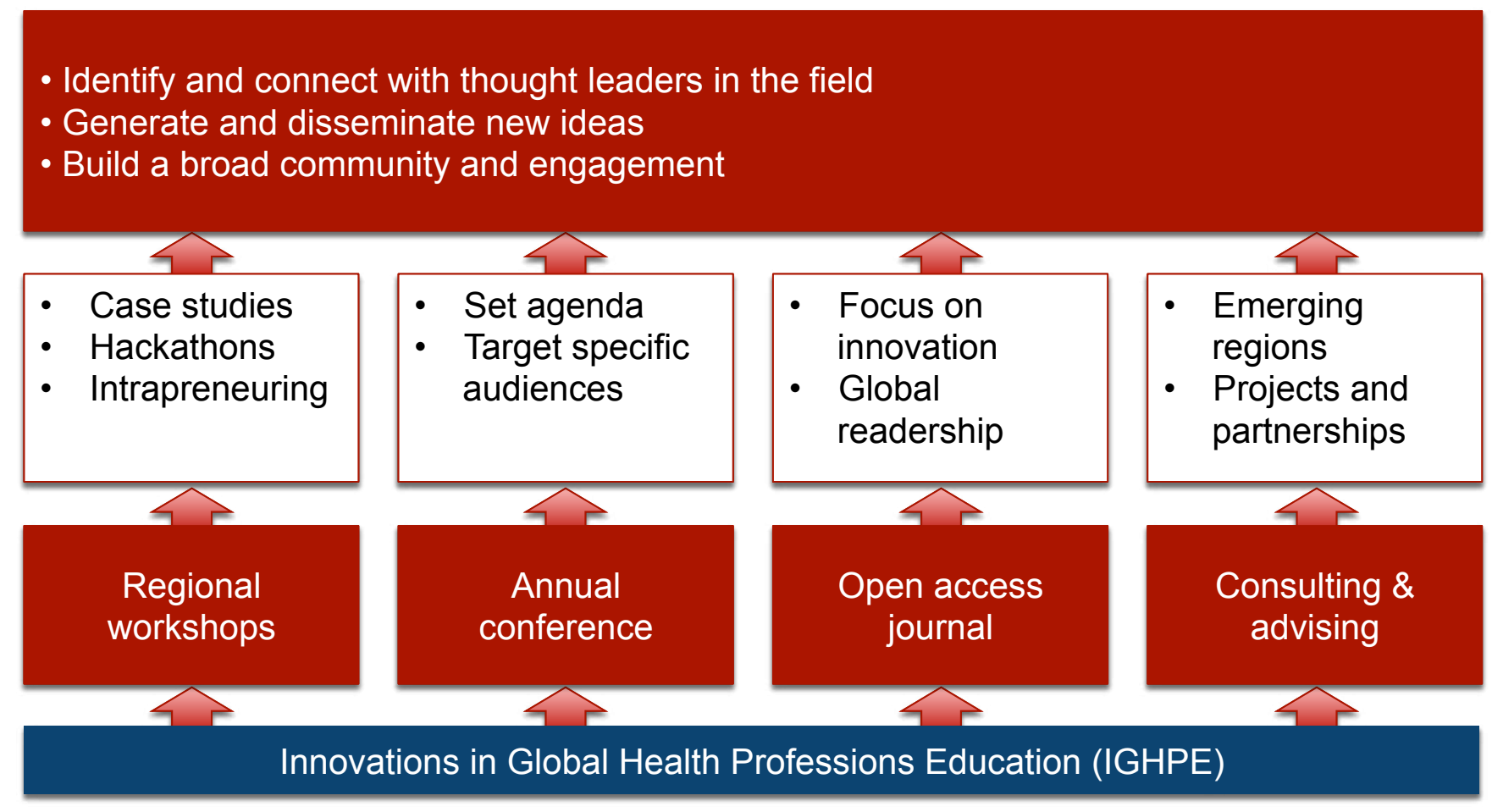

Figure 1. IGHPE as an organizing platform

education \& collaborative practice; 2010 [cited November 30, 2015]. Geneva: World Health Organization. Available from http:// whqlibdoc.who.int/hq/2010/WHO_HRH_ HPN_10.3_eng.pdf.

4. Interprofessional Education Collaborative (IPEC) [Internet]. About IPEC. Washington D.C.: IPEC; C. 2015 [cited 2015 November 30]. Available from https://ipecollaborative.org/ About_IPEC.html.

5. Association of American Medical Colleges [Internet]. Congressional Briefing Explores Interprofessional Education. 2015 [cited 2015 November 30]. Available from https://bit. Iy/2P3XI0x
6. Topol EJ. Individualized Medicine from Prewomb to Tomb. Cell 2014;157(1):241-53

7. Legg $M$. The role of informatics in the shift from reactive to proactive healthcare. EPMA J.;2014, 5 (Suppl 1): A50.

8. World Economic Forum [Internet]. New Vision for Education: Unlocking the potential of technology. Geneva: World Economic Forum. 2015 [cited 2015 November 30]. Available from http://www3.weforum.org/docs/WEFUSA_ NewVisionforEducation_Report2015.pdf. 